HEALTH PSYCHOLOGY REPORT · VOLUME 3(2), 2015 ORIGINAL ARTICLE
Magdalena Żemojtel-Piotrowska

$1 \cdot \mathrm{A}, \mathrm{B}, \mathrm{D}, \mathrm{E}, \mathrm{F}$

Jarostaw Piotrowski

$2 \cdot \mathrm{A}, \mathrm{B}, \mathrm{C}, \mathrm{D}, \mathrm{G}$

Amanda Clinton

$3 \cdot \mathrm{B}, \mathrm{D}, \mathrm{E}$

Jan Cieciuch

$4 \cdot \mathrm{B}, \mathrm{D}, \mathrm{E}, \mathrm{G}$

Joanna Różycka-Tran

$1 \cdot \mathrm{B}, \mathrm{D}$

Truong Thi Khanh $\mathrm{Ha}$

$5 \cdot \mathrm{B}, \mathrm{D}$

\title{
Entitlement and subjective well-being: a three-nations study
}

\section{BACKGROUND}

The current study investigated the role of three facets of entitlement (active, passive and revenge) in various forms of subjective well-being (SWB): hedonistic and two facets of eudaimonic well-being (social and psychological). Social well-being was based on Keyes' model (1998) and psychological well-being on Ryff's model (1989).

\section{PARTICIPANTS AND PROCEDURE}

The study was performed in three nations (Poland, Puerto Rico and Vietnam) on student samples (Poland, $n=245$, Vietnam, $n=115$, and Puerto Rico, $n=300$ ). To assess entitlement level the Entitlement Questionnaire was used. The level of hedonistic well-being was measured with the Satisfaction with Life Scale (SWLS) and the Positive and Negative Affect Schedule (PANAS), and eudaimonic well-being by the Mental Health Continuum-Short Form (MHC-SF).
RESULTS

Active entitlement was positively related to all aspects of SWB. Revenge entitlement was negatively related to hedonistic and psychological SWB in all samples and negatively related to social well-being only in Poland. Passive entitlement was unrelated to SWB.

\section{CONCLUSIONS}

The current study shows cross-cultural similarities in relationships of entitlement with hedonistic and psychological well-being and cross-cultural differences in the relationship of entitlement with social well-being. Additionally, the study indicates positive meaning of healthy aspects of entitlement for subjective well-being and negative meaning of dysfunctional aspects of entitlement for subjective well-being.

KEY WORDS

entitlement; hedonistic well-being; eudaimonic well-being

ORganization - 1: Institute of Psychology, University of Gdansk, Gdansk, Poland · 2: Institute of Psychology, University of Social Sciences and Humanities, Poznan Faculty, Poznan, Poland · 3: Institute of Psychology, University of Puerto Rico, Puerto Rico · 4: Institute of Psychology, Cardinal Stefan Wyszyński University in Warsaw, Warsaw, Poland .

5: Institute of Psychology, Vietnam National University, Vietnam aUthors' Contributions - A: Study design - B: Data collection - C: Statistical analysis - D: Data interpretation .

E: Manuscript preparation · F: Literature search · G: Funds collection

Corresponding Author - Magdalena Żemojtel-Piotrowska, Ph.D., Institute of Psychology, University of Gdansk,

4 Bażyńskiego Str., 80-952 Gdansk, Poland, e-mail: psymzp@ug.edu.pl

to Cite this ARTICle - Żemojtel-Piotrowska, M., Piotrowski, J., Clinton, A., Cieciuch, J., Różycka-Tran, J., \& Truong Thi,

K. H. (2015). Entitlement and subjective well-being: a three-nations study. Health Psychology Report, 3(2), $140-149$.

DOI: $10.5114 /$ hpr.2015.49635 


\section{BACKGROUND}

Psychological entitlement, defined as a pervasive sense that an individual deserves special treatment (Campbell, Bonacci, Shelton, Exline, \& Bushman, 2004; Twenge \& Campbell, 2009), is assumed to be negatively related to subjective well-being, as it plays a particular role in the link between narcissism and well-being (Twenge \& Campbell, 2009; Żemojtel-Piotrowska, Piotrowski, \& Maltby, 2015c). Subjective well-being refers to those aspects of well-being that are based on psychological variables, such as affectivity and evaluations of different aspects of an individual's life (Deci \& Ryan, 2008). It results in general life satisfaction (Deci \& Ryan, 2008; Diener, Emmons, Larsen, \& Griffin, 1985). However, both entitlement and well-being are rather complex and broad phenomena. For this reason, examination of the relationship between entitlement and subjective well-being should address the problem of entitlement's and subjective well-being's conceptual complexity. In the current study, we present results of research examining the relationship between three facets of entitlement - active, passive, and revenge (Piotrowski \& Żemojtel-Piotrowska, 2009) - and various forms of subjective well-being (SWB) - hedonistic and two facets of eudaimonic well-being (social and psychological) (Deci \& Ryan, 2008; Keyes, 1998; Ryff, 1989) - to address the complexity of both phenomena. The data were obtained from three countries: Poland, Vietnam and Puerto Rico. First, we aim to explore the problem how entitlement is related both to hedonic well-being and two facets of eudaimonic well-being with particular consideration of its social aspect. Then, we explore cross-cultural differences and similarities in these relationships, extending our findings to cultural contexts beyond Poland.

\section{PSYCHOLOGICAL ENTITLEMENT AND SUBJECTIVE WELL-BEING}

Hedonistic well-being is conceptualised as experiencing life satisfaction accompanied by positive balance between positive and negative affect (Deci \& Ryan, 2008). Diener et al. (1985) distinguished between its cognitive aspect, expressed in a broadly positive evaluation of life and its related domains, and its affective component, comprised by experiencing higher positive affect and lower (or lack of) negative affect (see also Carruthers \& Hood, 2004). Hedonistic well-being is based on the hedonic tradition in defining well-being as a pleasure.

According to Deci and Ryan's (2008) distinction, hedonic well-being is only one facet of broadly defined subjective well-being. The second important facet of well-being is based on the eudaimonic tradition of defining well-being as living well and actualizing the in- dividual's potential (Deci \& Ryan, 2008). Psychological well-being (Ryff, 1989) and social well-being (Keyes, 1998) constitute broadly defined eudaimonic well-being (see also Keyes, Shmotkin, \& Ryff, 2002). Both these aspects are highly positively correlated, or even hard to statistically distinguish, especially if they are measured by Keyes' (1998) Mental Health Continuum Scale (see Jovanovich, 2015). Psychological well-being is comprised by seeking meaning in life, self-acceptance, personal growth, autonomy, environmental mastery, and positive relations with others (Ryff, 1989). This latter aspect overlaps with social well-being, defined as positive evaluation of self in the social environment, comprised by social integrity, social acceptance, social contribution, social coherency, and social self-actualization (Keyes, 1998).

Psychological entitlement is typically defined as the pervasive sense that an individual is entitled to and deserves more than others (Campbell et al., 2004). A negative relationship between psychological entitlement, life satisfaction and individual social functioning is broadly assumed (Bishop \& Lane, 2002; Fisk, 2010; McGann \& Steil, 2005; Twenge, 2006; Twenge \& Campbell, 2009). However, recent work suggests that this negative relationship is limited to dysfunctional aspects of entitlement (e.g. Lessard, Greenberger, Chen, \& Faruggia, 2011; Rothman, 2012; Żemojtel-Piotrowska, Clinton, Piotrowski, Baltatescu, \& Van Hiel, 2013). To date, among many competitive approaches in examining entitlement as a complex phenomenon, it is the 3-dimensional model of entitlement that demonstrates cross-cultural validity across cultural contexts (Żemojtel-Piotrowska et al., 2014a). This model assumes three dimensions of entitlement: active, based on protection of self-interest; passive, focused on group interest with the conviction that institutions and others are obligated to satisfy their own needs; and revenge, which is based on the protection of self-interest when it is threatened or violated. Active and revenge entitlement correlate with psychological entitlement (Żemojtel-Piotrowska et al., 2015b); however, active entitlement seems to be a proactive and agentic aspect of psychological entitlement, while revenge entitlement seems to be a more dysfunctional and excessive phenomenon due to its positive correlation with unhindered agency (Żemojtel-Piotrowska, Piotrowski, \& Clinton, 2015a). Passive entitlement, postulated on the basis of the Central-European tradition of conceptualizing entitlement as expectations toward the state, is distinct from active and revenge entitlement. This is because it represents the communal aspect of formulation demands toward others in that it correlates positively with collective narcissism (Golec de Zavala, Cichocka, Eidelson, \& Jayawickreme, 2009) and communal narcissism (Gebauer, Sedikides, Verplanken, \& Maio, 2012), as well as entitlement syndrome (Lewicka, 2002), which contains expectations toward the state.
Entitlement and well-being in three nations 
Active and revenge forms of entitlement are related to hedonistic subjective well-being (SWB, i.e. satisfaction with life and positive affective balance): active entitlement is related positively to $S W B$, revenge entitlement is negatively related to SWB, and passive entitlement is unrelated to SWB (Żemojtel-Piotrowska et al., 2013). In prior studies only hedonistic well-being was measured. For this reason, little is known about the relationship between eudaimonic well-being and entitlement.

Magdalena

Żemojtel-

Piotrowska, Jarosław

Piotrowski, Amanda Clinton,

Jan Cieciuch, Joanna

Różycka-Tran, Truong Thi Khanh $\mathrm{Ha}$

\section{CURRENT RESEARCH}

Subjective well-being could be considered an outcome of entitlement. Dysfunctional aspects of entitlement are linked to lower life satisfaction, as a higher level of expectations could be associated with the feeling of disappointment when these expectations are not met. These assumptions are supported by findings on relationships between psychological entitlement and satisfaction with work (Harvey \& Martinko, 2009) and from a study on the relationship between relational entitlement and functioning in romantic relationships (Tolmacz \& Mikulincer, 2011). Highly entitled people manifest lower job satisfaction (Harvey \& Martinko, 2009) and lower satisfaction from romantic relationships (Tolmacz \& Mikulincer, 2011). However, more adaptive forms of entitlement could affect positively happiness, since formulating demands toward others increases one's chances of satisfying one's own needs. For instance, among several forms of relational entitlement, Tolmacz and Mikulincer (2011) identified a lack of entitlement, labelled by them as restrictive entitlement. This lack of entitlement in close relationships is related to lower life satisfaction similar to other dysfunctional forms of relational entitlement, but contrary to assertive relational entitlement (Tolmacz \& Mikulincer, 2011). Similar findings were reported by Żemojtel-Piotrowska, Piotrowski, and Baran (2014b) for three forms of entitlement and satisfaction with a close relationship: revenge entitlement was related negatively to satisfaction with a close relationship, whereas active entitlement was positively related to higher satisfaction (specifically, higher levels of perceived similarity to the partner and lower disappointment from him/her).

In the current study, we chose this direction of interrelations. We assumed that the relationship between hedonistic and eudaimonic psychological well-being and all facets of entitlement would be cross-culturally universal, and the relationship between entitlement and social well-being culturally specific. Both in individualistic and collectivistic societies, expectations toward others could result in increases in hedonism if the chances for satisfying one's own needs also increase. It is possible when these expectations are reasonable - rather than excessive in form - and when formulating expectations toward others does not mean discontinuing one's own activity. According to Welzel and Inglehart (2010), increasing the significance of agency results in higher levels of satisfaction with life. For this reason in individualistic societies life satisfaction is higher than in collectivistic ones. Since active entitlement is positively related to agency, or, more specifically, active pursuit of one's own goals and a focus on actions, and passive entitlement is positively related to communion, or, more specifically, a focus on interpersonal relations (Żemojtel-Piotrowska, et al., 2015a, see also Bakan, 1966; Helgeson \& Frizt, 1999), we hypothesize that active entitlement will increase levels of hedonistic well-being while passive entitlement will not. We do not formulate expectations related to revenge entitlement, since it is related to agency (Żemojtel-Piotrowska et al., 2015a) but not related to higher self-esteem (Piotrowski \& Żemojtel-Piotrowska, 2009). Since higher self-esteem is one of the most important predictors of hedonistic well-being ( $\mathrm{Di}-$ ener, Oishi, \& Lucas, 2003), this lack of interrelations between revenge entitlement and self-esteem points to the lack of a relationship between revenge entitlement and hedonistic well-being. Moreover, since revenge entitlement is positively related to unmitigated agency (Żemojtel-Piotrowska et al., 2015a), it could be potentially destructive for social well-being.

In relation to eudaimonic well-being, we assume that passive entitlement will be related positively to social well-being, as it is based on communion and a communal vision of the social world (ŻemojtelPiotrowska et al., 2015a). We also predict a negative relationship between revenge entitlement and social well-being, since insisting on revenge could be destructive for social relations and, furthermore, because revenge entitlement is associated with a negative vision of the social world, including close relationships (Żemojtel-Piotrowska et al., 2014b). Further, we assume that the relationship between entitlement and social well-being could be culturally diverse.

We tested our assumptions in three countries: Poland, Puerto Rico ${ }^{1}$ and Vietnam. They were chosen due to their cultural differences, as they represent three distinct geographical regions - Europe, Asia and Latin America. These countries differ in some important cultural, economic and political aspects. For example, in terms of Hofstede's dimensions (Hofstede, 2011; Hofstede, Hofstede, \& Minkov, 2010), Poland is an individualistic country, whereas Puerto Rico and Vietnam are collectivistic cultures. All three societies also differ on the dimension of indulgence. Indulgence is a dimension related to socialization of children and attitudes toward enjoying life and having fun. Poland and Vietnam are countries of low indulgence (i.e. restraint), and Puerto Rico is a country of high indulgence. This dimension could be particularly important from the perspective of formulating demands and expectations 
toward others. High indulgence manifests in allowing others free expression of their own needs, a focus on enjoying life and an emphasis on personal freedom and happiness. As such, formulating demands toward others may not be perceived as negative, since members of high indulgence cultures are more benevolent towards pursuit of personal freedom and assertiveness in pursuit of individual goals (Hofstede, 2011). On the other hand, in the countries of low indulgence (i.e. restraint), people could perceive formulating demands as egoism and lack of self-control. For this reason, we do not only expect differences in the relationship between entitlement and social well-being on the basis of collectivism (assuming mutual obligations) and individualism (assuming self-reliance), but also on the basis of the indulgence-restraint dimension. Furthermore, these three countries have different political systems, and political systems make a particularly important contribution to the formulation of expectations toward the state and others. According to the Economist Intelligence Unit (2015), for example, Poland is an invalid democracy. Puerto Rico, which is a territory of the United States, is considered a full democracy, and Vietnam is defined as an authoritarian regime. These three countries also vary in their respective levels of economic freedom (Economist Intelligence Unit, 2015). It is possible that formulating demands toward others could be positively related to subjective well-being in more affluent and effective social systems, while the contrary would be observed in less affluent societies, since there is a greater likelihood of expectations being fulfilled in the former, as these expectations have higher chances of being positively addressed.

Boski (2009) analysed the source of satisfaction with life both in Polish and Vietnamese samples. He found different sources of life satisfaction. These results were confirmed in another study that measured the adaptation and integration of Vietnamese and Slavic (Ukrainian, Russian, and Belarusian) immigrants in Poland (Boski \& Biłas-Henne, 2010). Different predictors of general life satisfaction were found: eudaimonia (e.g. thrift) was a major predictor of SWLS among the Vietnamese, and hedonism (e.g. spending extravaganza) was a major predictor for Slavic people. This reflects cultural differences between these two groups: whereas eudaimonia (frugality) is integrated into Confucian virtues (see Bond, 1983; Hofstede, 2001), hedonism (extravaganza) is incorporated into Slavic Sarmatism (Boski, 2009). Since the Caribbean region has not been studied in any depth by subjective well-being researchers, little is known about predictors of well-being in this cultural group. For instance, Morris, Martin, Hopson, and Welch-Murphy (2010) compared US youth with their Caribbean counterparts (namely, from Aruba), and they found no differences in the level of well-being among them; however, Caribbean participants reported fewer depressive symptoms overall.

\section{PARTICIPANTS AND PROCEDURE}

\section{PARTICIPANTS}

Five hundred and thirty-four students of social sciences and management (Poland, $n=245,31 \%$ men, Vietnam, $n=115,36 \%$ men, and Puerto Rico, $n=300$, $43 \%$ men) ranging in age from 16 years to 47 years $(M=21.47)$ participated in the study.

\section{MEASURES}

Entitlement. Entitlement attitudes were measured by the Entitlement Questionnaire - Short Form (Żemojtel-Piotrowska et al., 2015b). This scale consists of 15 items, five per scale. It serves as a measure of active entitlement (e.g. I deserve the best; It is necessary to claim what you deserve; I often demand to be treated properly), passive (Everybody has the right to expect help from the state when in need; Disadvantaged persons deserve institutional help; The state should take care of the livelihood of the poorest); and revenge (Someone who hurts me cannot expect my sympathy; I have difficulty forgiving harm done to me; I don't forgive the wrongs I have suffered). Participants answered questions on the scale with scores ranging from 1 or completely disagree to 6 or completely agree. The scale has proven reliability and validity (Piotrowski \& Żemojtel-Piotrowska, 2009; ŻemojtelPiotrowska et al., 2015b). Cronbach's $\alpha$ reliabilities of active, passive and revenge entitlement were, respectively, .80, .90, .81 in Poland, .72, .63, .80 in Puerto Rico, and .67, .67, .81 in Vietnam.

Hedonistic well-being. Hedonistic well-being was defined as general satisfaction with life and positive evaluation of its different aspects (cognitive component) and as a positive affective balance (affective component, see Diener et al., 1985). Based on the conception of Diener et al. (1985), we included two measures of cognitive well-being: the Personal Well-Being Index (PWI, International Wellbeing Group, 2013) and the Satisfaction with Life Scale (SWLS) (Diener et al., 1985) and a measure of affective well-being: the Positive and Negative Affect Schedule (PANAS) (Watson, Clark, \& Tellegen, 1988). The PWI contains 8 items, each one describing a specific domain. Participants answer (on a scale from 0 - completely not satisfied to 10 - totally satisfied) to what extent he or she is satisfied with a particular domain (e.g. future security or health) (see International Wellbeing Group, 2013). The SWLS is one of the most popular scales available for measuring general satisfaction with life. In the current study, participants answered questions on the scale with scores from 1 - strongly disagree to 5 - strongly agree (Diener et al., 1985). The PANAS serves as a measure of the affective component of well-being and contains 10 descriptions of
Entitlement and well-being in three nations 
Magdalena

Żemojtel-

Piotrowska, Jarosław

Piotrowski,

Amanda

Clinton,

Jan Cieciuch, Joanna

Różycka-Tran,

Truong Thi

Khanh $\mathrm{Ha}$ positive emotions (e.g. enthusiastic, happy) and 10 of negative emotions (e.g. frightened, upset). Participants are asked how often they have experienced a particular emotion within recent weeks. In the present study, we asked participants how they typically feel, and they answered on a scale ranging from 1 - very slightly or not at all to 5 - extremely (Watson et al., 1988).

Eudaimonic well-being. The Mental Health Continuum-Short Form was used to measure two facets of eudaimonic well-being. The scale contains 14 items, 6 of which serve as a measure of social well-being as defined by Keyes (1998), and 6 of which serve as a measure of psychological well-being as defined by Ryff (1989). We omitted the emotional well-being subscale since we were interested only in the social and psychological aspects of eudaimonic well-being. These items are the most representative for the long form and are intended to cover whole constructs. The structure of the scale was confirmed in confirmational factor analysis (CFA) (see Karaś, Cieciuch, \& Keyes, 2014).

\section{STATISTICAL ANALYSES}

To examine the relationships between entitlement attitudes and different aspects of subjective well-being, we conducted structural equation modelling (SEM) in each country separately. In the first step we assessed a measurement model for entitlement and each form of well-being in each country separately, which was composed of six latent factors: active, passive, and revenge entitlement, hedonistic well-being, social well-being and psychological well-being. Then we ran multi-group confirmatory factor analyses to determine whether we achieved measurement invariance of methods across countries. Model 1 assumed configural invariance, i.e. the same structure of scales (number of factors and pattern of loadings) across countries. Model 2 assumed metric invariance, i.e. equivalence of factor loadings across countries. Metric invariance allows comparison between structural models in our three national samples (see Steinmetz et al., 2005).

After establishing metric invariance we ran SEM analyses in each country separately, examining the interrelations between entitlement and different aspects of well-being, i.e. a structural model. Finally, we compared different solutions, assuming cross-cultural differences with regard to all interrelations (unconstrained model) and assuming similarity in the relationship between entitlement and those aspects of well-being that were unrelated to others (i.e. hedonistic and psychological) and cultural differences in the relationship between entitlement and social well-being, as reflecting social functioning of the individual (constrained models).

\section{RESULTS}

\section{MEASUREMENT MODEL}

To test for measurement models we used confirmatory factor analysis parcels (2-3 aggregated items) as observed variables. The parcelling was used to reduce

Table 1

Model fit indices for measurement models in three nations - single confirmational factor analysis

\begin{tabular}{lccccc}
\hline \multicolumn{1}{l}{$\chi^{2}$} & $d f$ & CFI & RMSEA & SRMR \\
\hline Entitlement Questionnaire - SF (three latent factors, each of them loaded by two parcels) & \\
Poland & 6.49 & 6 & .999 & $.018(<.001 .087)$ & .024 \\
Puerto Rico & 7.05 & 6 & .998 & $.024(<.001 .082)$ & .034 \\
Vietnam & 9.62 & 6 & .980 & $.073(<.001 .154)$ & .039
\end{tabular}

Hedonistic well-being (one latent factor loaded by four parcels: summated scores of PWI, SWLS, and Negative affectivity and Positive affectivity from the PANAS, estimate errors for the PANAS scales correlated)

$\begin{array}{lccccc}\text { Poland } & 0.08 & 1 & 1.00 & <.001(<.001 .111) & .004 \\ \text { Puerto Rico } & 2.97 & 1 & .994 & .081(<.001 .195) & .018 \\ \text { Vietnam } & 1.15 & 1 & .998 & .037(<.001 .255) & .026 \\ \text { Social and psychological well-being (two latent factors, each of them loaded by two parcels) } \\ \begin{array}{l}\text { Poland } \\ \text { Puerto Rico }\end{array} \\ \begin{array}{l}\text { Vietnam } \\ \text { Pietna }\end{array} & 2.58 & 1 & .993 & .121(.028 .242) & .011 \\ \end{array}$


estimation errors (Coffman \& MacCallum, 2005), improve model fit, and stabilize parameter estimates (see Matsunaga, 2008). We tested four models: in the first one three entitlement factors were loaded by parcels created in random fashion (each factor loaded by two parcels), in the second one the latent factor of hedonistic well-being was loaded by results obtained in the PWI, SWLS, and Negative affectivity and Positive affectivity from the PANAS (which served as substantive parcels), and in the third one the latent factors of eudaimonic and social wellbeing were loaded by parcels, created in random fashion from MHC items intended to measure the appropriate constructs. All latent factors were measured by at least two parcels and all parcels loaded on a proper factor significantly ( $p<.001$, all factor loadings higher than .40 with the exception of Negative affectivity from the PANAS). To assess the goodness of fit of the model we used the following cut-off criteria: the root mean square error of approximation (RMSEA) and standardized root mean square residual (SRMR), both smaller than .08, and comparative fit index (CFI) larger than .90 (see Lance, Butts, \& Michels, 2006 for a review).

Table 1 shows that the measurement model fits the data well in each country separately.

A problem could be noted with regard to social and psychological well-being in Puerto Rico, as they were highly positively correlated.
In the next step we established measurement invariance of the measured constructs across three countries. Because we were interested in relationships between the variables, we tested for the metric level of measurement invariance.

Table 2 shows that metric invariance was established for each measurement model, and in consequence all variables measured in the study, because in all cases $\triangle \mathrm{CFI}$ was lower than .01 , meeting the recommended cut-off of .01 (Chen, 2007).

\section{STRUCTURAL MODEL}

The structural model assessed the impact of entitlement attitudes on subjective well-being. It was assumed that three facets of entitlement influence subjective well-being, both hedonistic and eudaimonic (psychological and social). Based on former research, described in the introduction, we examined the influence of active and revenge entitlement on hedonic, psychological and social well-being and the influence of passive entitlement on psychological and social well-being.

Table 3 shows the fit indices for the structural model in each country separately. In each sample the structural model fits the data well.

In the next step we assessed three competitive models: one unconstrained, assuming all direct paths as diverse across countries (Model 1); fully constra-

Table 2

Results for multi-group confirmatory factor analysis

\begin{tabular}{|c|c|c|c|c|c|}
\hline & $\chi^{2}$ & $d f$ & CFI & RMSEA & SRMR \\
\hline \multicolumn{6}{|c|}{ Entitlement Questionnaire - SF (three latent factors, each of them loaded by five items) } \\
\hline Configural & 23.19 & 18 & .996 & $.021(<.001 .043)$ & .024 \\
\hline Metric & 36.01 & 24 & .992 & $.028(<.001 .045)$ & .024 \\
\hline \multicolumn{6}{|c|}{$\begin{array}{l}\text { Hedonistic well-being (one latent factor loaded by four parcels: summated scores of PWI, SWLS, and } \\
\text { Negative affectivity and Positive affectivity from the PANAS) }\end{array}$} \\
\hline Configural & 4.20 & 3 & .998 & $.025(<.001 .074)$ & .004 \\
\hline Metric & 7.37 & 9 & 1.00 & $<.001(<.001 .038)$ & .024 \\
\hline \multicolumn{6}{|c|}{ Social and psychological well-being (two latent factors, each of them loaded by two parcels) } \\
\hline Configural & 32.55 & 3 & .977 & $.122(.087 .162)$ & .011 \\
\hline Metric & 35.42 & 7 & .978 & $.079(.054 .105)$ & .017 \\
\hline
\end{tabular}

Table 3

Goodness of fit indices for structural model in three nations

\begin{tabular}{lccccc}
\hline & $\chi^{2}$ & $d f$ & CFI & RMSEA & SRMR \\
\hline Poland & 134.00 & 62 & .958 & $.069(.053 .085)$ & .052 \\
Puerto Rico & 122.83 & 62 & .964 & $.057(.042 .072)$ & .048 \\
Vietnam & 94.17 & 62 & .942 & $.067(.037 .094)$ & .071 \\
\hline
\end{tabular}


Table 4

Model fit indices for measurement models in three nations

\begin{tabular}{lccccc}
\hline & $\chi^{2}$ & $d f$ & CFI & RMSEA & SRMR \\
\hline Model 1: Unconstrained & 351.18 & 186 & .958 & $.037(.031 .043)$ & .052 \\
Model 2: Constrained & 627.58 & 246 & .903 & $.049(.044 .053)$ & .063 \\
Model 3: Partially constrained & 361.50 & 196 & .958 & $.036(.030 .042)$ & .056 \\
\hline
\end{tabular}

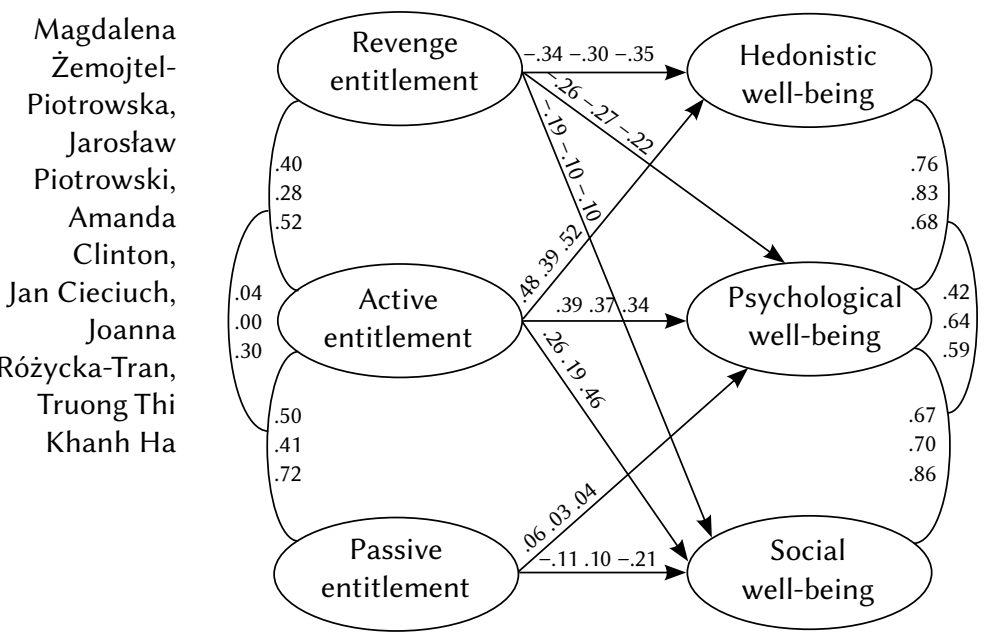

Note. Non-significant standardized regression weights are underlined. Regression coefficients are presented in the following order: Poland, Puerto Rico, Vietnam. Only latent factors are presented in Figure 1, without observed variables.

Figure 1. Structural unconstrained model presenting the relationship between entitlement attitudes and subjective well-being.

ined, assuming regression weights equal across countries (Model 2); and partially constrained, assuming that the relationships between entitlement and psychological and hedonic well-being are equal across countries and the relationship between entitlement and social well-being differs across countries (Model 3). Table 4 shows indices for the fit of models.

Model comparisons indicated that Model 1 (unconstrained) did not differ significantly from Model 3 $(\triangle \mathrm{CFI}=.00)$. Model 2 differs significantly from both Model 1 and Model $3(\Delta \mathrm{CFI}=.06)$, despite fitting the data.

As predicted, cross-cultural differences were observed only for the relationship between entitlement attitudes and social well-being (see Figure 1). Relationships between active entitlement and hedonistic and psychological well-being were positive, congruent with predictions. Revenge entitlement was related negatively to both hedonistic well-being and psychological well-being. Passive entitlement was unrelated to psychological well-being.
Active entitlement was related positively to social well-being in all three countries. Direct comparisons between the strength of relationship between these two variables in three countries revealed no significant differences ( $Z$ ranged from 0.34 for the Poland-Vietnam comparison to 1.25 for the Puerto Rico-Vietnam comparison, all insignificant). Passive entitlement was unrelated to social well-being in all three countries. Revenge entitlement was negatively related to social well-being only in Poland, an individualistic culture of high restraint $(\beta=-.18, p=.001)$.

Generally, only the aspects of entitlement that were related to individual interest (i.e. active and revenge entitlement) were correlated with aspects of subjective well-being that are related to satisfying individual needs. Active entitlement seems to be particularly profitable for individual well-being. This supports Welzel and Inglehart's (2010) thesis that increasing the level of agency can increase one's life satisfaction.

\section{CONCLUSIONS}

Despite their preliminary and exploratory character, the current findings support the authors' thesis about cross-cultural similarities in terms of a positive relationship between the agentic, non-narcissistic form of entitlement and different aspects of subjective well-being. This result is distinct from the negative, costly effect of psychological entitlement on life satisfaction (Twenge \& Campbell, 2009; Żemojtel-Piotrowska et al., 2015c). Revenge entitlement, as related to narcissism (Piotrowski \& Żemojtel-Piotrowska, 2009; see also Exline \& Zell, 2009) and dissatisfaction with close relationships (Żemojtel-Piotrowska et al., 2014b), was predicted to be negatively related to subjective well-being, especially the social aspect. These assumptions were confirmed in relation to hedonism and psychological well-being, and - partially - to social well-being (in Poland). Since revenge seems to be especially dysfunctional in terms of interpersonal relationships, its relatively lesser impact on social well-being (in comparison to hedonistic and psychological aspects) is surprising. However, vengefulness and vindictiveness are often related to neuroticism (Bellah, Bellah, 
\& Johnson, 2003), as observed in the current research and supported in previous research findings. Passive entitlement, contrary to predictions, did not demonstrate a relationship with any aspect of subjective well-being, although a positive relationship with social well-being, particularly in collectivistic cultures, was anticipated. However, the results did not support this assumption. The lack of a relationship between passive entitlement and subjective well-being is congruent with the lack of a relationship between passive entitlement and satisfaction with close relationships (Żemojtel-Piotrowska et al., 2014b) and its independence from hedonic well-being (ŻemojtelPiotrowska et al., 2013). Finally, congruent with predictions, we found cultural differences in relationships between entitlement and social well-being, but they were limited to vengefulness. Revenge entitlement is undesirable only in Poland, an individualistic country with a high level of restraint, with a hedonic tradition in shaping general well-being.

\section{LIMITATIONS AND SUGGESTIONS FOR FURTHER WORK}

The current research is preliminary in character. The participants were young, well-educated individuals. Student samples are not representative for research in general. However, results obtained in research such as the present work could serve as a source for further investigation and hypotheses. In spite of this limitation, however, it is important to note that we found similar results for countries on three distinct continents and with different political and cultural traditions. Another limitation is the lack of inclusion of countries with low power distance in terms of Hofstede's (2011) model. Research suggests that certain amounts of cross-cultural generalization may be acceptable; however, there is still little known about the myriad cultural and political contexts of the world. In the current study, social and psychological well-being demonstrated a strong positive correlation. For this reason, one could doubt whether both aspects of eudaimonia should be distinguished, in line with Jovanovich's critique (2015), stating that there should not be separate scores for the respective subscales of the MHC-SF. However, we found some differences in correlations between entitlement and both facets of eudaimonic well-being. Finally, despite our causality assumptions (i.e., that entitlement affects subjective well-being), the opposite direction of interrelations is also plausible.

The work of Jarostaw Piotrowski was supported by grant awarded by University of Social Sciences and Humanities, Poznan Faculty and the work of Jan Cieciuch was supported by Grants DEC-2011/01/D/HS6/04077 from the Polish National Science Centre.

\section{References}

Bakan, D. (1966). The duality of human existence. Chicago: Rand McNally.

Bellah, C. G., Bellah, L. D., \& Johnson, J. L. (2003). A look at dispositional vengefulness from the three and five-factor models of personality. Individual Differences Research, 1, 6-16.

Bishop, J., \& Lane, R. C. (2002). The dynamics and dangers of entitlement. Psychoanalytic Psychology, 19, 739-758. DOI: 10.1037//0736-9735.19.4.739

Bond, M. H. (1983). How language variation affects inter-cultural differentiation of values by Hong Kong bilinguals. Journal of Language and Social Psychology, 2, 57-67.

Boski, P. (2009). Kulturowe ramy zachowań spotecznych [Cultural framing of social behaviours]. Warsaw: Scholar.

Boski, P., \& Biłas-Henne, M. (2010). Stowianie zza wschodnich granic oraz Wietnamczycy w Warszawie: Różnice kulturowe w adaptacji psychologicznej imigrantów [Slavs from behind the eastern border and the Vietnamese in Warsaw: Cultural differences in psychological adaptation of immigrants]. Paper presented at the conference of SWPS Warszawiacy z Wietnamu i zza wschodniej granicy, Warsaw.

Campbell, K.W., Bonacci, A. M., Shelton, J., Exline, J. J., \& Bushman, B. J. (2004). Psychological entitlement: Interpersonal consequences and validation of self-report measure. Journal of Personality Assessment, 83, 29-45.

Carruthers, C., \& Hood, C. (2004). The power of the positive: Leisure and well-being. Therapeutic Recreation Journal: Special Issue on Health and Health Promotion, 38, 225-245.

Chen, F. F. (2007). Sensitivity of goodness of fit indexes to lack of measurement invariance. Structural Equation Modeling, 14, 464-504.

Coffman, D. L., \& MacCallum, R. C. (2005). Using parcels to convert path analysis models into latent variable models. Multivariate Behavioral Research, 40, 235-259.

Deci, E. L., \& Ryan, R. M. (2008). Hedonia, eudaimonia and well-being: An introduction. Journal of Happiness Studies, 9, 1-11. DOI: 10.1007/s10902006-9018-1

Diener, E., Emmons, R. A., Larsen, R. J., \& Griffin, S. (1985). The Satisfaction with Life Scale. Journal of Personality Assessment, 49, 71-75.

Diener, E., Oishi, S., \& Lucas R. E. (2003). Personality, culture and subjective well-being: Emotional and cognitive evaluations of life. Annual Review of Psychology, 54, 403-425. DOI: 10.1146/annurev. psych.54.101601.145056

Exline, J. J., \& Zell, A. L. (2009). Empathy, self-affirmation, and forgiveness: The moderate roles of gender and entitlement. Journal of Social and
Entitlement and well-being in three nations 
Clinical Psychology, 28, 1071-1099. DOI: 10521/ jscp.2009.28.09.1071

Fisk, G. M. (2010). "I want it all and I want it now!" An examination of the etiology, expression, and escalation of excessive employee entitlement. Human Resource Management Review, 20, 102-114. DOI: 10.1016/j.hrmr.2009.11.001

Gebauer, J. E., Sedikides, C., Verplanken, B., \& Maio, G. R. (2012). Communal narcissism. Journal of Personality and Social Psychology, 103, 854-878. DOI: 10.1037/a0029629

Magdalena

Żemojtel-

Piotrowska,

Jarosław

Piotrowski,

Amanda

Clinton,

Jan Cieciuch, Joanna

Różycka-Tran,

Truong Thi

Khanh $\mathrm{Ha}$

Golec de Zavala, A., Cichocka, A., Eidelson, R., \& Jayawickreme, N. (2009). Collective narcissism and Organizational Behavior, 30, 459-476.

Helgeson, V. S., \& Fritz, H. (1999). Unmitigated agenits social consequences. Journal of Personality and Social Psychology, 97, 1074-1096. DOI: 10.1037/ a0016904

Harvey, P., \& Martinko, M. J. (2009). An empirical examination of the role of attributions in psychological entitlement and its outcomes. Journal of cy and unmitigated communion: Distinctions from agency and communion. Journal of Research in Personality, 33, 131-158.

Hofstede, G. (2001). Culture's consequences: Comparing values, behaviors, institutions and organizations across nations. Thousand Oaks CA: Sage Publications.

Hofstede, G. (2011). Dimensionalizing cultures: The Hofstede model in context. Online Readings in Psychology and Culture, 2. http://dx.doi.org/ 10.9707/2307-0919.1014

Hofstede, G., Hofstede, G. J., \& Minkov, M. (2010). Cultures and Organizations: Software of the Mind (rev. $3^{\text {rd }}$ ed.). New York: McGraw-Hill.

International Wellbeing Group (2013). Personal Wellbeing Index: $5^{\text {th }}$ edition. Melbourne: Australian Centre on Quality of Life, Deakin University.

Jovanovich, V. (2015). Structural validity of Mental Health Continuum - Short Form: The bifactor model of emotional, social and psychological well-being. Journal of Personality and Individual Differences, 75, 154-159. DOI: 10.1016/j. paid.2014.11.026

Lance, C. E., Butts, M. M., \& Michels, L. C. (2006). The sources of four commonly reported cut-off criteria: what did they really say? Organization Research Methods, 9, 202-220.

Lessard, J., Greenberger, E., Chen, C., \& Farruggia, S. (2011). Are youth feelings of entitlement always 'bad'? Evidence for a distinction between exploitive and non-exploitive dimensions of entitlement. Journal of Adolescence, 34, 521-529. DOI: 10.1016/j.adolescence.2010.05.014

Lewicka, M. (2002). Daj czy wypracuj? Sześcienny model aktywności [Give or work out? Six-dimensional activity model]. In: M. Lewicka, \& J. Grzelak (eds.), Jednostka i społeczeństwo. Podejście psy- chologiczne [Individual and society. Psychological approach] (pp. 83-102). Gdansk: GWP.

Karaś, D., Cieciuch, J., \& Keyes, C. L. M. (2014). The Polish Adaptation of the Mental Health Continuum-Short Form (MHC-SF). Personality and Individual Differences, 69, 104-109.

Keyes, C. L. M. (1998). Social well-being. Social Psychology Quarterly, 61, 121-140.

Keyes, L. M., Shmotkin, D., \& Ryff, C. D. (2002). Optimizing well-being: The empirical encounter of two traditions. Journal of Personality and Social Psychology, 8, 1007-1022. DOI: 10.1037//00223514.82.6.1007

Matsunaga, M. (2008). Item parceling in structural equation modeling: A primer. Communication Methods and Measures, 2, 260-293. DOI: 10.1080/19312450802458935

McGann, V., \& Steil, J. (2005). The sense of entitlement. Implications for gender inequality and psychological well-being. In: J. Worell (ed.), Handbook of girls' and women's psychological health. New York: Oxford University Press.

Morris, R. W., Martin, B., Hopson, J., \& Welch-Murphy, K. (2010). Besides that I'm OK: Well-being in Caribbean and American Adolescents and Youth. Journal of Research on Christian Education, 19, 56-78.

Piotrowski, J., \& Żemojtel-Piotrowska, M. (2009). Kwestionariusz roszczeniowości [Entitlement Questionnaire]. Roczniki Psychologiczne, 12, 151-177.

Rothman, A. M. (2012). Adolescent attachment and entitlement in a world of wealth. Journal of Infant, Child, and Adolescent Psychotherapy, 11, 53-65. DOI: 10.1080/15289168.2012.650002

Ryff, C. D. (1989). Happiness is everything, or is It? Explorations on the meaning of psychological well-being. Journal of Personality and Social Psychology, 57, 1069-1081.

Steinmetz, H.,Schmidt, P.,Tina-Booh,A.,Wieczorek,S., \& Schwartz, S. H. Testing measurement invariance using multigroup CFA: differences between educational groups in human values measurement. Qualitative Quantitative, 43, 599-616.

The Economist Intelligence Unit (2015). Retrieved on 25 January 2015 from http://www.eiu.com/home. aspx.

Tolmacz, R., \& Mikulincer, M. (2011). The sense of entitlement in romantic relationships - Scale construction, factor structure, construct validity, and its associations with entitlement orientations. Psychoanalytic Psychology, 28, 75-94. DOI: 10.1037/a0021479

Twenge, J. (2006). Generation me: Why today's young Americans are more confident, assertive, entitled-and more miserable than ever before. New York: Free Press.

Twenge, J., \& Campbell, W. K. (2009). The narcissism epidemic. Life in the age of entitlement. New York: Free Press. 
Watson, D., Clark, L. A. \& Tellegen, A. (1988). Development and validation of brief measures of positive and negative affect: The PANAS scales. Journal of Personality and Social Psychology, 54, 1063-1070.

Waterman, A. S. (1993). Two conceptions of happiness: Contrasts of personal expressiveness (eudaimonia) and hedonic enjoyment. Journal of Personality and Social Psychology, 64, 678-691. DOI: 10.1037/0022-3514.64.4.678

Welzel, C., \& Inglehart, R. (2010). Agency, values and well-being: A Human Development Model. Social Indicators Research, 97, 43-63. DOI: 10.1007/ s11205-009-9557-z

Żemojtel-Piotrowska, M., Clinton, A., Piotrowski, J., Baltatescu, S., \& Van Hiel, A. (2013). Materialism, subjective well-being, and entitlement. Journal of Social Research and Policy, 4, 79-91.

Żemojtel-Piotrowska, M., Piotrowski, J., Argentero, P., Baltatescu, S., Bardhwaj, G., Bukowski, M., Calogero, R., Chargazia, M., Clinton, A., Halik, M. H., Ilisko, D., Khachatryan, N., Klicperova-Baker, M., Kovacs, M., Letovancova, E., Liik, K., Michałowski, J., Nord, I., Paspalanova, E., Perez de Leon, P., Techera, J., Rojas, M., Różycka, J., Seibt, B., Semkiv, I., Tiliouine, H., Truong, H. K., Van Hiel, A., van den Bos, K., \& Wills-Herrera, E. (2014a). Kulturowe wymiary postaw roszczeniowych. Psychologia Spoteczna, 29, 220-240.

Żemojtel-Piotrowska, M., Piotrowski, J., \& Baran, T. (2014b). Roszczeniowość a satysfakcja ze związku intymnego [Entitlement and satisfaction with intimate relationships]. Studia Psychologiczne, 52, 21-32.

Żemojtel-Piotrowska, M., Piotrowski, J., \& Clinton, A. (2015a). Agency, communion and three forms of entitlement. International Journal of Psychology, in press. DOI: 10.1002/ijop. 12140

Żemojtel-Piotrowska, M. A., Piotrowski, J. P., Cieciuch, J., Calogero, R. M., Van Hiel, A., Argentero, P., Baltatescu, S., Baran, T., Bardhwaj, G., Bukowski, M., Chargazia, M., Clinton, A., Halik, M. H., Ilisko, D., Khachatryan, N., Klicperova-Baker, M., Kostal, J., Kovacs, M., Letovancova, E., Liik, K., Marganski, A., Michalowski, J., Nord, I., Paspalanova, E., Perez de Leon, P., Techera, J., Rojas, M., Różycka-Tran, J., Sawicka, A., Seibt, B., Semkiv, I., Tiliouine, H., Truong Thi, K. H., van den Bos, K., Wills-Herrera, E. (2015b). Measurement of psychological entitlement in 28 countries. Manuscript submitted for publication.

Żemojtel-Piotrowska, M., Piotrowski, J., \& Maltby, J. (2015c). Agentic and communal narcissism and satisfaction with life: The mediating role of psychological entitlement and self-esteem. Manuscript submitted for publication. 